references to recent, but already well-known, work on the nerve supply, vascular architecture, and histochemistry of the gland. In his preface, Dr. Bourne tells us that his book is part of a thesis he submitted for the degree of doctor of science in Australia in 1934. It is a pity that a book which certainly contains some useful information could not have been brought up to date before publication, nor orientated, at any rate partly, along modern lines as well as along the more traditional lines of comparative anatomy.

\section{CALCULATING THE FLOW OF HEAT}

Heat Conduction

With Engineering and Geological Applications. By Prof. Leonard R. Ingersoll, Otto J. Zobel and Alfred C. Ingersoll. (International Series in Pure and Applied Physies.) Pp. xii +278 . (New York and London: McGraw-Hill Book Co., Inc., 1948.) $24 s$.

IN contrast to the other two modes by which heat 1 may be transferred, conduction has been the subject of much successful work by theorists as well as by experimentalists. To the former, the calculation of heat flow means the evaluation of the field of temperature in a homogeneous substance when either the temperature or the heat flow is given at each point on the boundaries. If, then, heat enters or leaves the substance by radiation or convection, the phenomenon is taken into account only in the boundary conditions.

The methods available for solving this boundary problem are varied; they include the use of the Fourier or the Laplace transform, which in many cases removes from consideration the time as an independent variable. In simpler cases, the solution may be obtained as the sum of an infinite series of the normal functions for the equation, these functions depending, of course, on the co-ordinates used for the space variables. Other solutions are obtained by the use of the Green's function, or by making use of the concept of sources and sinks, just as in hydrodynamics.

This book is best described as an introduction, but only an introduction, to the mathematical calculation of heat conduction, and with a marked bias towards the physics of the problem. The simpler methods among those mentioned above are described and illustrated; but the use of conformal transformations and of Laplace transforms is not mentioned, and no methods calling for advanced mathematics are used. The physical outlook makes the book very stimu. lating for those who have problems of this sort to solve in practice, but would probably be repellent to a mathematician. To him, an approximation to the solution of a problem which he cannot solve explicitly means an expression which differs from the solution by an amount to which he can set an upper limit. Here, he would find 'approximations' which consist in changing tho boundary conditions. For example, instead of a boundary condition in which heat loss is proportional to temperature excess, a fictitious layer of material may be added, the boundary of which is not allowed to change in temperature. To the applied physicist, however, this treatment will appeal as an ingenious device for getting an approximate idea of the course of the temperature with time, when the problem as originally formulated could not be solved by the methods at his command.

The book treats separately the steady state, periodic regimes, and non-steady regimes, with 'linear' flow treated separately in each case because of the simplicity obtained when there is only one spatial co-ordinate. Numerical, graphical and analogical methods of solving the equation of heat conduction are considered, as well as formal solutions, and there is an interesting chapter on the formation of ice. The book should be useful to mathematicians who take up practical work, and to practical men themselves, though both should realize that there is more aid to be obtained from mathematics than is shown here.

J. H. AWBERY

\section{ARCTIC EXPLORATION}

\section{To the Arctic!}

The Story of Northern Exploration from Earliest Times to the Present. By Jeannette Mirsky. Pp. xxii $+334+x$ viii +12 plates. (London and New York: Allan Wingate (Publishers), Ltd., 1949.) 21s. net.

T is not easy-and perhaps ill-advised from pros1 pects of popular acceptance to write a history of polar exploration without a bias to the heroic, sentimental or patriotic. A mere catalogue of expeditions would make dull reading, and the most successful and least adventurous efforts are generally monotonous in their records. The epic of shipwreck, hunger and scurvy provides popular sensation; but very often these are signs of faulty organisation.

The author of this large work has not altogether escaped the longing for the picturesque, but gives it no undue prominence. She dwells fully on much American and Russian work and gives details of such ghastly failures as the Greely expedition of 1881-84 and De Long in the Jeanette. Nansen's crossing of Greenland, which marked a great advance in technique, rightly has full notice ; but several later and more successful crossings, such as that of Lindsay, are omitted. Details of Russian work, including seventeenth- and eighteenth-century work in Arctic Siberia, and modern work in the same area, are welcome since they are rarely available to English readers. The long story of the Franklin search is well told, with due emphasis on Rae's work. The travelling methods of the men of the Hudson's Bay Co, are shown in violent contrast to the naval technique of those days. Nor do the Admiralty and the leader of its expeditions, especially Belcher, escape well-merited criticism, even if some of their journeys were marvels of grit and endurance. The work is full and accurate, and a chapter on Arctic aviation brings it well up to modern times.

Miss J. Mirsky does not claim to mention every expedition, for her compilation is no mere catalogue. Perhaps Glen's work in North East Land should have found a place, and Norwegian aerial surveys in Svalbard also merit notice. Mistakes are rare and trivial. Jan Mayen's peak has an unfamiliar title. Rae can scarcely be said to have tried a crossing of Greenland, and $a$ distinguished Spitsbergen explorer is wrongly credited with a university chair. There are some good illustrations and adequate maps. The book is a great improvement on the first edition, published in 1934 as "To the North".

R. N. Rudmose Brown 